\title{
The Relationship between Serum Total Oxidant Status, Total Antioxidant Status, and Oxidative Stress Index with Severity Levels of Gastroesophageal Reflux Disease: A Literature Review
}

\author{
Tri Asih Imro'ati ${ }^{1 *} \mathbb{D}$, Titong Sugihartono ${ }^{2}$, Budi Widodo ${ }^{2}$, Eva Pravitasari Nefertiti ${ }^{3}$, Ivan Rovian ${ }^{4}$, I Gede Nyoman Wibawa ${ }^{5}$ \\ ${ }^{1}$ Department of Internal Medicine, Gastroenterohepatology Division, Faculty of Medicine, Universitas Airlangga, Universitas \\ Airlangga Hospital, Surabaya, Indonesia; ${ }^{2}$ Department of Gastroenterohepatology, Faculty of Medicine, Universitas Airlangga, \\ Dr. Soetomo Academic Hospital, Surabaya, Indonesia; ${ }^{3}$ Department of Histopathology, Faculty of Medicine, Universitas Hang \\ Tuah, Surabaya, Indonesia; ${ }^{4}$ Department of Internal Medicine, Faculty of Public Health, Universitas Airlangga, Surabaya, \\ Indonesia; ${ }^{5}$ Department of Gastroenterohepatology, Sanglah Hospital, Bali, Indonesia
}

\begin{abstract}
Gastroesophageal reflux disease (GERD) is a global health problem in which the prevalence is increasing over periods. This disease is a significant cause of disorders in the upper gastrointestinal tract with very complex pathogenesis. Oxidative stress (OS) due to gastric acid reflux plays a role in the inflammatory response of the esophageal epithelium. Several OS markers have been widely studied and are thought to affect the severity degree of the esophageal mucosa. However, there has been no research on total oxidant status (TOS), total antioxidant status (TAS), and OS index (OSI) in the adult with GERD; hence the aim of this review was to determine the association between TOS, serum TAS, and OSI with the GERD degree. A literature review was conducted by searching articles related to the TOS, TAS, OSI, and its correlation with GERD degree on an online database, particularly Pubmed and Google scholar. We conclude that TAS and OSI might influence the severity of GERD; however, further clinical study is needed to prove this theory.
\end{abstract}

Edited by: Mirko Spirosk Citation: Imro'ati TA, Sugihartono T, Widodo B, efertiti EP, Rovian I, Wibawa IGN. The Relationship between Serum Total Oxidant Status, Total Antioxidan Status, and Oxidative Stress Index with Severity Levels of Gastroesophageal Reflux Disease. A Literature Review. https///doi. org/10.3889/oamims 2021.7346 https://doi.org/ $10.3889 /$ oamjms. 2021.7346 Keywords: Gastroesophageal reflux; Total oxidative status; Total antioxidant status; Oxidative stress index,

*Correspondence: Tri Asih Imro'ati, Department of Internal Medicine, Gastroenterohepatology Division, Universitas Airlangga Hospital, Faculty of Medicine, Universitas Airlangga, Surabaya, Indonesia. E-mail: triasihimroati.unair@gmail.com Received: 04-Jun-202 Revised: 29-Sep-202

\section{Introduction}

The prevalence of gastroesophageal reflux is predicted around $8-33 \%$ [1] and increases over Southeast Asia from $6.3 \%$ in 2005 to $18.3 \%$ in 2010 [2]. In Indonesia, gastroesophageal reflux appeared to be specific in esophagitis, with the number of cases reached $5.7 \%$ in 1997 and rose to $25.18 \%$ in 2002 [3].

Aside from its effect on the gastrologic system, this disease is known as a costly disease. Since the patients are required to charge other medication options, should the first treatment provide a positive outcome. Moreover, if acid suppression therapy fails and the patient seeks a second opinion or receives a higher dose or a different type of proton pump inhibitor. About $55 \%$ of patients have persistent symptoms of Gastroesophageal reflux disease (GERD) and have impaired quality of life [2]. Some conditions identic with esophageal reflux's pathogenesis are hyperacidity, abdominal pressure, food, drugs, and anatomical factors [4]. High gastric acid stimulates oesophageal epithelial cells to create reactive oxygen species (ROS) and cause oxidative stress (OS) by activating macrophages, Proteinase-Activated Receptor 2 (PAR 2), and Platelet-Activating Factor [5]. The inflammatory process will be aided by OS, eventually resulting in mucosal damage [6].

Researchers have been fascinated by the function of OS in oesophageal mucosal damage. Because OS plays a key role in the oesophageal epithelium's inflammatory response, treatments that target OS could be a novel approach to GERD treatment, particularly in individuals who have chronic symptoms while getting appropriate treatment [7]. Several studies utilizing esophageal tissue have been 
conducted on OS in GERD; however, no investigations on the expression of oxidants and tissue antioxidants have been conducted in Indonesia. The presence of increased total oxidant status (TOS) decreased TAS, and elevated OS index (OSI) in blood serum can indicate OS. Low overall antioxidant capacity may suggest OS or increase oxidative damage sensitivity [8]. When antioxidants work cooperatively, they provide better protection against reactive oxygen and nitrogen species assaults than if they performed separately. Afterward, it is critical to look at the total antioxidant capacity [9].

The low total antioxidant capacity may indicate OS or increase susceptibility to oxidative damage [8]. The collaboration between antioxidants improves protection against ROS and reactive nitrogen species (RNS) attacks than each component. Then, it is essential to examine the total antioxidant capacity [9]. Breast and thyroid cancer have been analyzed using OS characteristics such as TOS, TAS, and OSI [10]; however, GERD research is still limited.

By using a systematic approach to the literature, this study aimed to provide an overview of the association between Serum TOS, TAS, and OSI with Severity Levels of GERD.

\section{Definition and Classification of Severity}

GERD happens is a condition when repeated gastric contents reflux happens into the esophagus causes mucosal breaks in the esophagus and symptoms that interfere with the quality of life or cause complications [3], [11], [12]. Symptoms can be moderate-to-severe and can occur on one or more days per week [4].

Based on the Los Angeles classification, the severity of GERD can be divided into 4 degrees, namely [13]: (A) Grade A: when there is a number of mucosal breaks $(=>5 \mathrm{~mm})$ and it does not extend between the crests of 2 mucosal folds; (B) Grade B: when there is several mucosal break of above $5 \mathrm{~mm}$ and it does not extend between the crests of the two mucosal folds; (C) Grade C: if there are some mucosal breaks that continues between the crests of 2 or more mucosal folds but is $<75 \%$ esophageal circumference; (D) Grade D: if there are some mucosal breaks involving more than $75 \%$ of the esophageal circumference[13].

\section{Mechanism of Reflux}

The fundamental mechanisms of GERD are structural and functional abnormalities of the esophagogastric junction (EGJ) and impaired esophageal clearance [14]. Eosinophilic Esophagitis (EE) results from chemical injury and burning acids. EE was assumed to occur spontaneously when the esophageal squamous epithelium was exposed to refluxed gastric juices such as acid and pepsin. However, according to other studies, reflux issues are caused by the immune system's participation and inflammation. Acid and pepsin, in particular, have been shown to cause severe macroscopic damage to esophageal squamous cells. Inflammatory mediators are released by damaged and inflamed tissue, which the immune system detects. In addition, endothelial cells create adhesion molecules in reaction to these substances, which adsorb and activate leukocytes, resulting in inflammatory conditions [7], [15].

Reflux generally occurs through four mechanisms, namely: (1) transient relaxation of the lower esophageal sphincter (LES); (2) low pressure on LES; (3) relaxation of LES caused by swallowing; and (4) increased intra-abdominal pressure in periods of low-pressure LES [16], [17], [18].

Transient relaxation of LES is believed to be the most common mechanism of reflux in conditions of normal LES tone $(>10 \mathrm{mmHg})$. The state of transient relaxation is said to cause $90 \%$ of reflux in patients without a hiatal hernia. In patients with hiatal hernia, reflux is more common in conditions of low-pressure LES, increased intra-abdominal pressure, and relaxation of LES due to swallowing [17], [18], [19], [20], [21].

The anti-reflux shield is the main factor determining the weight and mechanism of reflux. This protective system is formed from the synergy between the LES and the crural diaphragm. The protective function of this anatomical zone is maintained by the architecture of the gastroesophageal valve, which is reinforced by the pharyngoesophageal ligament and sling fibers of the gastric cardia. This reinforcing structure maintains the intrinsic position of the LES in the extrinsic region of the crural diaphragm so that the two anatomical structures can fuse and form an antireflux barrier. Damage to the anti-reflux barrier will be related to the severity of reflux [16], [18], [22], [23].

LES is a short segment in the distal esophagus that is formed from smooth muscle. LES at rest has a tone between 10 and $30 \mathrm{mmHg}$, depending on gastric pressure. This LES tone usually provides adequate protection against the pressure gradient in the EGJ. LES tone is influenced by myogenic and neurogenic factors, which are further influenced by intra-abdominal pressure, gastric dilatation, peptides, hormones, food, and drugs [21], [22], [23].

LES function is a significant risk factor for GERD. LES has a period of transient relaxation, during which GERD symptoms are common. The transient relaxation of LES occurs for 10-45 s, which makes room for the stomach to expel gas in the form 
of belching. The frequency of LES transient relaxation did not differ in GERD patients and normal people. Still, GERD patients were reported to experience GERD symptoms during the SEB transient relaxation period [24].

Reflux of gastric contents will cause lesions and symptoms, which depends on the duration of exposure to the gastric contents and the degree of acidity. The duration of reflux exposure depends on the effectiveness of reflux clearance, which has three components: peristalsis, salivation, and the presence or absence of a hiatal hernia. This reflux clearance disorder will further be closely related to complications of GERD, while esophageal sensitivity will be related to the patient's perception of GERD symptoms [16], [17], [18], [19], [20].

\section{OS}

OS is a broad term that refers to a significant imbalance between ROS production and antioxidant defense mechanisms, which can result in potentially dangerous conditions. ROS can damage membrane lipids and DNA, as well as alter cell protein activity, under these conditions. OS could be implicated in the etiology of numerous illnesses, both as a cause and as a result, and may have a part in the deterioration in body function (aging process) [25], [26], [27], [28]. OS indicates an imbalance between systemic manifestations of ROS and the capacity of biological systems, which detoxify oxidant agents or repair damaged organisms [29].

ROS can be produced by the cytoplasm, mitochondria, and peroxisomes [26]. ROS are free radicals (superoxide anions $\left[\mathrm{O}^{-}{ }_{2}\right]$, hydroxyl radicals, peroxyl and alkoxyl radicals) and compounds that can produce radicals in situ (hydrogen peroxide $\left[\mathrm{H}_{2} \mathrm{O}_{2}\right]$, singlet oxygen, hypohalous acid). The physiologically redox-active metals iron and copper can act as catalysts for the activation of the latter species. Direct detection of free radical levels in biological fluids is difficult because of their very short half-lives. Various methods for measuring all OS have been developed, but none are widely recognized [25].

The OS pathway and inflammation are inextricably linked. The oxidant activates the transcription of nuclear factor kappa B (NF- $\mathrm{B} B)$ ), which stimulates proinflammatory molecules. On the other hand, inflammation causes OS because the production of free radicals is material for immune cell activation. The interaction between OS and inflammation can play an essential role in the pathogenesis of several diseases in humans, such as GERD, gastritis, enteritis, colitis, and cancer [28], [29].

\section{TOS}

The following is the TOS examination principle: (1) the oxidant in the sample oxidizes the iron ion-chelator complex; (2) the oxidation reaction is prolonged by enhancer molecules abundant in the reaction medium; (3) in an acidic medium, the iron ion forms a colored complex with the chromogen; (4) color intensity, which can be measured by spectrophotometry, is related to the total number of oxidant molecules present in the sample.

The results are reported in micromolar $\mathrm{H}_{2} \mathrm{O}_{2}$ equivalent per liter (mol $\mathrm{H}_{2} \mathrm{O}_{2}$ Equiv./L) and are calibrated with $\mathrm{H}_{2} \mathrm{O}_{2}$ [30]. Samples that can be used are blood serum, plasma with heparin, semen plasma, urine, cell lysate, and tissue homogenate. Serum samples are stable for up to 1 week at $4^{\circ} \mathrm{C}, 6$ months at $-20^{\circ} \mathrm{C}$, and 1 year at $-80^{\circ} \mathrm{C}$ [30].

\section{TAS}

The antioxidant defense system consists mainly of protein enzymes and endogenous small molecules (vitamins E, C, carotenoids, reduced glutathione), which neutralize oxygen radicals. Superoxide dismutase (SOD) copper/zinc, glutathione peroxidase (GPx) selenium, and TAS are part of the cellular defense system. SOD catalyzes the dismutation of $\mathrm{O}^{-}{ }_{2}$ into $\mathrm{H}_{2} \mathrm{O}_{2}$, which is then neutralized by GPx or catalase. Because they sequester transition metals like copper and iron and prevent them from participating in oxidative processes, uric acid, albumin, bilirubin, total protein, ferritin, transferrin, and haptoglobin are considered tertiary antioxidants. Dynamic interactions between numerous biological components, including enzymatic and non-enzymatic antioxidant systems, dictate antioxidant status [31]. TAS estimated the global antioxidant rate of subjects.

When weakened antioxidant defenses, body cells and tissues become more susceptible to dysfunction and disease; maintaining adequate but not excessive antioxidant levels is essential for preventing or even treating many disease conditions. Examination of total antioxidant capacity can be a valuable biomarker of disease in biochemistry, medicine, food, and nutrition. The total antioxidant capacity examination can be a reliable biomarker for diagnostic and prognostic purposes in specific conditions such as heart and blood vessel disease, diabetes mellitus, neurological disorders, psychiatry, kidney and lung disorders, malignancy, and chronic inflammatory enteropathy. However, it needs some attention in its use, such as choice of method, use of other antioxidant biomarkers such as cell antioxidants, 
antioxidant-response elements, or antioxidant vitamins [32]. The TAS is higher in men than women at any age. Albumin and uric acid levels in men, women, and girls, and total protein in men are significant determinants of TAS levels [31].

The oxidation and antioxidant status of serum are often checked in serum that has been frozen for some time. In contrast, the OS process tends to change rapidly in the sample due to the instability of the reactants. Jansen et al. investigated the performance and stability of human serum samples on short-term storage ( 3 and $48 \mathrm{~h}$ ), concluded that handling serum samples at temperatures of +4 and $+20^{\circ} \mathrm{C}$ in the short term did not affect the quality and performance of the oxidation and antioxidant assays during the analysis from day to other days [33].

\section{OSI}

OSI is one of the OS parameters obtained from the calculation of the ratio of TOS to TAS, which is a more accurate OSI in the body because it is produced from comprehensive measurements of TOS and TAS [34], [35].

OSI is the index most often used in the literature, especially in patients with cardiovascular disease, pregnancy disorders, psychiatric disorders, infectious diseases, cancer, skin disorders, oral diseases, respiratory diseases, metabolic disorders, and other disorders. The index calculation in this study used more biological samples than blood, such as semen, urine, cerebrospinal fluid, amniotic fluid, vaginal cleansing fluid, gingival crevicular fluid, saliva, and aqueous humor [35].

\section{Relationship between TOS, Antioxidant Status and OSI with GERD Degree}

According to multiple recent researches, oxygen-freeradicalshavebeenassociated toesophageal mucosal injury in both animals and humans. ROS are extremely reactive molecules produced naturally in the body. Its production appears to be enhanced as part of the inflammatory response, and it causes oxidative damage to cells by damaging DNA, proteins, and cell membranes. An antioxidant defense mechanism protects cells from the harmful effects of ROS during cellular metabolism in normal circumstances. When OS occurs as a result of pathogenic events, the defense system increases the regulation and synthesis of antioxidant enzymes such as SOD, catalase, and GPx, which are cellular defense mechanisms against ROS. $\mathrm{O}^{-}{ }_{2}$ generation as the primary free radical in esophageal mucosal deterioration has been established in many experimental models of acute and chronic esophagitis. Human studies have discovered a relationship between mucosal free radical levels and the severity of esophagitis, with endogenous antioxidant defense systems' efficacy playing a significant role in preventing esophageal mucosal injury. Despite the fact that several free radical scavengers have been shown to protect esophageal mucosa in animals, research into the expression, activity, and relevance of endogenous enzymatic antioxidant systems in humans is currently limited [36].

Research Oh et al. in rats showed that high OS levels cause ER in the esophageal mucosa and that antioxidant therapy should be considered supplementation therapy with acid suppression in the prevention and treatment of ER [37].

The research of Jiménez et al. reduced antioxidant activity of SOD may have a role in esophageal damage and Barrett's esophagus in GERD patients, leading to increased mucosal production of $\mathrm{O}^{-}{ }_{2}$ and peroxynitrite radicals, as well as additional cell damage. In reaction to OS, glutathione levels, and catalase activity rise. SOD administration could thus be a therapeutic target in the management of ER and complications including Barrett's esophagus, according to the findings [36].

The role of antioxidants in the pathogenesis of ER, Barrett's esophagus, and esophageal adenocarcinoma are still unknown [38]. However, research by Karajibani et al. [29] stated that pro-oxidant and antioxidant balance (PAB) can be considered as predictors for the evaluation of OS in GERD patients so that the assessment of PAB together with other risk factors for ER can be used in the diagnosis and reduce complications disease [29].

Deng et al. [6] investigated the association between the severity of reflux esophagitis (GERD group and ER group) in children and changes in OS, serum inflammation, vasoactive intestinal peptide (VIP), and motilin. The study concluded that patients with reflux esophagitis had OS (by measuring changes in MDA levels, total SOD, VIP, motilin, IL-1 $\beta$, IL-8, and TNF) and elevated robust inflammatory response serum VIP (motility regulators), gastrointestinal tract, and decreased motilin levels. Controlling changes in the above factors using effective therapy means improving the development of GERD [6].

The effect of each factor on the development of esophagitis can be seen in Figure 1. Inflammatory mediator profiles in GERD indicate elevated levels of inflammatory components such as ROS, RNS, COX, NOS, MPO, and HIF in the esophageal mucosa, indicating an inflammatory response. As a result of an increase in these factors, damage to the esophagus 
mucosa increases, which can lead to esophageal cancer as if it is not addressed [15].

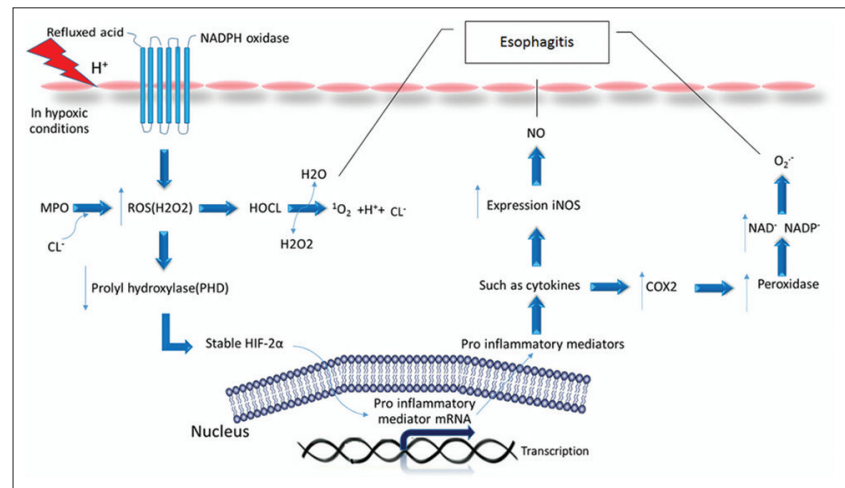

Figure 1: Effects of each factor on the development of esophagitis [15]

OS conditions can be seen from the increased TOS, decreased TAS, and increased OSI. Low total antioxidant capacity may indicate OS or increased susceptibility to oxidative damage [8].

\section{Conclusion}

Since TOS, TAS and OSI are the components to measure OS condition, the possibility to interpret the severity of GERD is highly likely to be done by referencing these values.

\section{References}

1. Gyawali CP, Kahrilas PJ, Savarino E, Zerbib F, Mion F, Smout AJ, et al. Modern diagnosis of GERD: The Lyon consensus. Gut. 2018;67(7):1351-62. https://doi.org/10.1136/ gutjnl-2017-314722

PMid:29437910

2. Ang $\mathrm{D}$, How $\mathrm{CH}$, Ang TL. Persistent gastro-oesophageal reflux symptoms despite proton pump inhibitor therapy. Singapore Med J. 2016;57(10):546-51. https://doi.org/10.11622/smedj.2016167 PMid:27779277

3. Indonesian Society of Gastroenterology (ISG). National consensus on the management of constipation in Indonesia 2010. Acta Med Indones. 2011;43(4):267-74.

\section{PMid:22156361}

4. Hunt R, Armstrong D, Katelaris P, Afihene M, Bane A, Bhatia S, et al. World gastroenterology organisation global guidelines: GERD global perspective on gastroesophageal reflux disease. J Clin Gastroenterol. 2017;51(6):467-78. https://doi.org/10.1097/ MCG.0000000000000854

PMid:28591069

5. Altomare A, Guarino MPL, Cocca S, Emerenziani $S$, Cicala M. Gastroesophageal reflux disease: Update on inflammation and symptom perception. World J Gastroenterol. 2013;19(39):6523-6528. https://doi.org/10.3748/wjg.v19.i39.6523 PMid:24151376

6. Deng Y, Pan L, Qian W. Associations between the severity of reflux esophagitis in children and changes in oxidative stress, serum inflammation, vasoactive intestinal peptide and motilin. Exp Ther Med. 2019;18(5):3509-13. https://doi.org/10.3892/ etm.2019.7978

PMid:31602227

7. Souza RF, Bayeh L, Spechler SJ, Tambar UK, Bruick RK. A new paradigm for GERD pathogenesis. Not acid injury, but cytokine-mediated inflammation driven by HIF-2 $\alpha$ : A potential role for targeting HIF-2 $\alpha$ to prevent and treat reflux esophagitis. Curr Opin Pharmacol. 2017;37:93-9. https://doi.org/10.1016/j. coph.2017.10.004

PMid:29112883

8. Young I. Measurement of total antioxidant capacity. J Clin Pathol. 2001;54(5):339. https://doi.org/10.1136/jcp.54.5.339 PMid:11328830

9. Apak R, Gorinstein S, Böhm V, Schaich KM, Özyürek M, Güçlü K. Methods of measurement and evaluation of natural antioxidant capacity/activity (IUPAC Technical Report). Pure Appl Chem. 2013;85(5):957-98. https://doi.org/10.1351/pac-rep-12-07-15

10. Huang Q, Feng J, Wu R, Yang Y, Dai C, Li J, et al. Total oxidant/ antioxidant status in sera of patients with esophageal cancer. Med Sci Monit. 2017;23:3789-94. https://doi.org/10.12659/ MSM.902210 PMid:28777781

11. Iwakiri $\mathrm{K}$, Kinoshita $\mathrm{Y}$, Habu $\mathrm{Y}$, Oshima $\mathrm{T}$, Manabe $\mathrm{N}$ Fujiwara $\mathrm{Y}$, et al. Evidence-based clinical practice guidelines for gastroesophageal reflux disease 2015. J Gastroenterol. 2016;5(8):751-67. https://doi.org/10.1007/s00535-016-1227-8 PMid:27325300

12. Sollano JD, Romano RP, Ibañez-Guzman L, Lontok MA, de Ocampo SQ, Policarpio AA, et al. Clinical practice guidelines on the diagnosis and treatment of gastroesophageal reflux disease (GERD). Phil J Intern Med. 2015;53(3):1-17.

13. Sami SS, Ragunath K. The Los Angeles classification of gastroesophageal reflux disease. Video J Encyclopedia GI Endosc. 2013;1(1):103-4. https://doi.org/10.1016/ S2212-0971(13)70046-3

14. Savarino E, Bredenoord AJ, Fox M, Pandolfino JE, Roman S, Gyawali CP, et al. Advances in the physiological assessment and diagnosis of GERD. Nat Rev Gastroenterol Hepatol. 2017;14(11):665-76. https://doi.org/10.1038/nrgastro.2017.130 PMid:28951582

15. Nejat Pish-Kenari F, Qujeq D, Maghsoudi $H$. Some of the effective factors in the pathogenesis of gastro-oesophageal reflux disease. J Cell Mol Med. 2018;22(12):6401-4. https://doi. org/10.1111/jcmm.13939 PMid:30320456

16. Tack J, Pandolfino JE. Pathophysiology of gastroesophageal reflux disease. Gastroenterology. 2018;154(2):277-88. https:// doi.org/10.1053/j.gastro.2017.09.047 PMid:29037470

17. Menezes MA, Herbella FA. Pathophysiology of gastroesophageal reflux disease. World J Surg. 2017;41(7):1666-71. https://doi. org/10.1007/s00268-017-3952-4 PMid:28258452

18. Herregods TV, Bredenoord AJ, Smout AJ. Pathophysiology of gastroesophageal reflux disease: New understanding in a new era. Neurogastroenterol Motil. 2015;27(9):1202-13. https://doi. org/10.1111/nmo.12611

PMid:26053301

19. Orlando RC. Pathophysiology of gastroesophageal reflux disease. J Clin. Gastroenterol. 2008;42(5):584-8. https://doi. org/10.1097/mcg.0b013e31815d0628 PMid:18364588

20. Lee YY, McColl KE. Pathophysiology of gastroesophageal reflux 
disease. Best Prac Res Clin Gastroenterol. 2013;27(3):339-51. https://doi.org/10.1016/j.bpg.2013.06.002

PMid:23998973

21. Kahrilas PJ, Pandolfino JE. Pathophysiology of gastroesophageal reflux disease. In: Fisichella $P$, Soper $N$, Pellegrini C, Patti M, editors. Surgical Management of Benign Esophageal Disorders. London: Springer; 2014. p. 11-24. https://doi.org/10.1007/978-1-4471-5484-6_2

22. Zachariah RA, Goo T, Lee RH. Mechanism and pathophysiology of gastroesophageal reflux disease. Gastrointest Endosc Clin N Am. 2020;30(2):209-26. https://doi.org/10.1016/j. giec.2019.12.001

PMid:32146942

23. Diamant NE. Pathophysiology of gastroesophageal reflux disease. GI Motil Online. 2006;168-173. https://doi.org/10.1038/ gimo21

24. MacFarlane B. Management of gastroesophageal reflux disease in adults: A pharmacist's perspective. Integr Pharm Res Pract. 2018;7:41-52. https://doi.org/10.2147/iprp.s142932 PMid:29892570

25. Buico A, Cassino C, Ravera M, Betta PG, Osella D. Oxidative stress and total antioxidant capacity in human plasma. Redox Rep. 2009;14(3):125-31. https://doi. org/10.1179/135100009X392557

PMid:19490754

26. Forrester SJ, Kikuchi DS, Hernandes MS, Xu Q, Griendling KK. Reactive oxygen species in metabolic and inflammatory signaling. Circ Res. 2018;122(6):877-902. https://doi. org/10.1161/circresaha.117.311401 PMid:29700084

27. Jozanov-Stankov O, Duric J, Dobutovic B, Isenović ER. Determination of total antioxidant status (TAS) as a biochemical parameter in control of workers health. Arch Biol Sci. 2009;61(3):375-82. https://doi.org/10.2298/abs0903375j

28. Li Y, Browne RW, Bonner MR, Deng F, Tian L, Mu L. Positive relationship between total antioxidant status and chemokines observed in adults. Oxid Med Cell Longev. 2014;2014:693680. https://doi.org/10.1155/2014/693680 PMid:25254081

29. Karajibani M, Bakhshipour AR, Montazerifar F, Dashipour A, Rouhi S, Moradpor M. Pro-oxidant and antioxidant balance, anthropometric parameters, and nutrient intakes in gastroesophageal reflux disease patients. Zahedan J Res Med Sci. 2018;20(4):e58553. https://doi.org/10.5812/zjrms.58553
30. Erel O. A new automated colorimetric method for measuring total oxidant status. Clin Biochem. 2005;38(12):1103-11. https:// doi.org/10.1016/j.clinbiochem.2005.08.008

PMid: 16214125

31. Habdous $M$, Herbeth $B$, Vincent-Viry $M$, Lamont JV, Fitzgerald PS, Visvikis $\mathrm{S}$, et al. Serum total antioxidant status, erythrocyte superoxide dismutase and whole-blood glutathione peroxidase activities in the Stanislas cohort: Influencing factors and reference intervals. Clin Chem Lab Med. 2003;41(2):209-15. https://doi.org/10.1515/cclm.2003.034 PMid:12667009

32. Kusano C, Ferrari B. Total antioxidant capacity: A biomarker in biomedical and nutritional studies. J Cell Mol Biol. 2008;7(1):1-5.

33. Jansen EH, Beekhof PK, Cremers JW, Viezeliene D, Muzakova V, Skalicky J. Short-term stability of biomarkers of oxidative stress and antioxidant status in human serum. ISRN Biomark. 2013;2013:316528. https://doi.org/10.1155/2013/316528

34. Wu R, Feng J, Yang Y, Dai C, Lu A, Li J, et al. Significance of serum total oxidant/antioxidant status in patients with colorectal cancer. PLoS One. 2017;12(1):e0170003. https://doi. org/10.1371/journal.pone. 0170003

PMid:28103261

35. Sánchez-Rodríguez MA, Mendoza-Núñez VM. Oxidative stress indexes for diagnosis of health or disease in humans. Oxid Med Cell Longev. 2019;2019:4128152. https://doi. org/10.1155/2019/4128152 PMid:31885788

36. Jiménez P, Piazuelo E, Sánchez MT, Ortego J, Soteras $F$, Lanas A. Free radicals and antioxidant systems in reflux esophagitis and Barrett's esophagus. World J Gastroenterol. 2005;11(18):2697-703. https://doi.org/10.3748/wjg.v11.i18.26 PMid:15884106

37. Oh TY, Lee JS, Ahn BO, Cho H, Kim WB, Kim YB, et al. Oxidative stress is more important than acid in the pathogenesis of reflux oesophagitis in rats. Gut. 2001;49(3):364-71. https:// doi.org/10.1136/gut.49.3.364 PMid:11511558

38. Murphy SJ, Anderson LA, Ferguson HR, Johnston BT, Watson PR, McGuigan J, et al. Dietary antioxidant and mineral intake in humans is associated with reduced risk of esophageal adenocarcinoma but not reflux esophagitis or Barrett's esophagus. J. Nutr. 2010;140(10):1757-63. https://doi. org/10.3945/jn. 110.124362

PMid:20702746 